Analisis Perkembangan Pembayaran SPP secara Online di suatu Universitas UMITRA

\title{
Tri Setiawan
}

165100094

Fakultas Komputer

trisetiawan.student@umitra.ac.id

\begin{abstract}
Perkembangan teknologi yang begitu cepat menuntut Universitas untuk memberikan pelayanan yang optimal kepada siswanya khususnya di UMITRA. Meningkatkan kualitas sistem informasi merupakan salah satu cara untuk mendukung pelayanan terhadap siswa. Sistem informasi pembayaran administrasi dirancang sesuai dengan keadaan di sekolah. Pengumpulan data dilakukan dengan menggunakan metode interview dan Metode observasi. Penelitian ini menghasilkan perancangan sistem informasi menggunakan Microsoft Visual basic 6.0 yang dapat membantu UMITRA untuk memberi pelayanan dalam pembayaran administrasi siswanya.
\end{abstract}

Kata kunci : Sistem Informasi, pembayaran administrasi, UMITRA. 


\section{PENDAHULUAN}

Meskipun penerapan teknologi informasi terus berkembang, akan tetapi pada kenyataannya masih terdapat instansi - instansi yang belum tersentuh dengan adanya teknologi informasi itu sendiri, seperti halnya pembayaran Administrasi siswa di UMITRA masih menggunakan proses pencatatan untuk menangani proses pembayaran Administrasi siswa, sehingga timbul suatu permasalahan dalam hal keefektifan dan efisiensi pengelolaan data menjadi sebuah informasi dalam proses manajemen sekolah. Karena dalam lingkungan pendidikan, pemanfaatan teknologi informasi sangat penting, dan harus dapat digunakan untuk berbagai keperluan.

Pada dasarnya sebuah lembaga maupun organisasi yang memanfaatkan teknologi informasi secara optimal yang dapat bertahan dalam era global ini, karena lewat pemanfaa- tan teknologi informasi sebuah lembaga atau organisasi dapat mengaskses informasi dengan cepat, tepat dan akurat serta dapat memberikan pelayanan yang efektif dan efisien. Seiring dengan terus bertambahnya jumlah siswa pada UMITRA Kabupaten Madiun menuntut lembaga sekolah untuk bisa memberikan pelayanan terbaik bagi siswa dalam pemanfaatan sarana maupun prasarana pendukung proses pembelajaran.

Dari beberapa hal tersebut dapat dilihat mengenai perlunya pembangunan sebuah sistem informasi khususnya sistem informasi administrasi siswa untuk diterapkan dalam proses pengolahan data administrasi siswa. Pada rencana perancangan Sistem Informasi Pembayaran Administrasi Siswa hendaknya sistem yang direncanakan akan mampu menyelesaikan permasalahan menyangkut sistem pembayaran administrasi siswa di UMITRA Bandar Lampung. 


\section{METODE PENELITIAN}

- Konsep Dasar Sistem Informasi

- Sistem

Konsep dasar sistem ada dua pendekatan yaitu penekanan pada prosedurnya dan penekanan pada komponennya atau elemen.

Pendekatan pertama adalah pendekatan sistem yang lebih menekankan pada prosedurnya didefinisikan oleh Jerry Fitzgerald, yang mendefinisikan suatu sistem adalah suatu jaringan kerja dari prosedur-prosedur yang saling berhubungan, berkumpul bersama-sama untuk melakukan suatu kegiatan atau untuk menyelesaikan suatu sasaran yang tertentu[1].

Pendekatan kedua adalah pendekatan sistem yang lebih menekankan pada komponen atau elemennya, mendefinisikan suatu sistem adalah kumpulan dari elemen-elemen yang berinteraksi untuk mencapai suatu tujuan tertentu.

\section{- Informasi}

Informasi adalah data yang telah diolah menjadi bentuk lain yang lebih berguna atau bernilai bagi yang pemakai dan dapat dijadikan sebagai bahan dalam pengambilan keputusan. Sumber dari informasi adalah data. Data adalah kenyataan yang menggambarkan suatu kejadian-kejadian dan kesatuan kenyataan. Data merupakan bentuk yang masih mentah sehingga perlu diolah lebih lanjut agar mempunyai nilai atau kegunaan bagi pemakainya. Kualitas informasi tergantung pada beberapa hal yaitu:
- Akurat, berati informasi harus bebas dari kesalahan-kesalahan.

- Tepat waktu, informasi yang diterima harus tepat pada waktunya.

- Relevan, informasi harus mempunyai manfaat bagi penerima.

*Sistem Informasi

Informasi merupakan hal yang sangat penting di dalam pengambilan sebuah keputusan. Informasi dapat diperoleh dari sistem informasi (information systems). sistem informasi adalah suatu sistem di dalam suatu organisasi yang mempertemukan kebutuhan pengolahan transaksi harian, mendukung operasi, bersifat manajerial dan kegiatan strategi dari suatu organisasi dan menyediakan pihak luar tertentu dengan laporanlaporan yang diperlukan.

- Konsep Dasar Administrasi Pembayaran Siswa

Administrasi adalah rangkaian kegiatan yang berupa proses pengendalian usaha kerja sama sekelompok manusia untuk mencapai tujuan bersama yang telah ditetapka sebelumnya. [3] dan administrasi pembayaran siswa merupakan suatu kegiatan administrasi yang melayani semua pembayaran siswa baik di lembaga pendidikan formal maupun non formal agar berlangsung secara efektif dan efisien dalam mencapai tujuannya. 
- Model Pengembangan perangkat lunak

Penelitian ini menggunakan proses Waterfall Model sebagai pola pengembangan sistem. Definisi yang diartikan oleh Roger S. Pressman dalam bukunya Software Engineering : Seventh Edition dijelaskan bahwa : -Waterfall Model sebuah proses perancangan yang secara berurutan dan sering digunakan dalam proses pengembangan perangkat lunak.l Menurut Pressman Waterfall Model adalah model klasik yang bersifat sistematis, berurutan dalam membangun software.

Berikut ini gambaran dari Waterfall Model.

Fase-fase dalam Waterfall Model menurut Pressman :

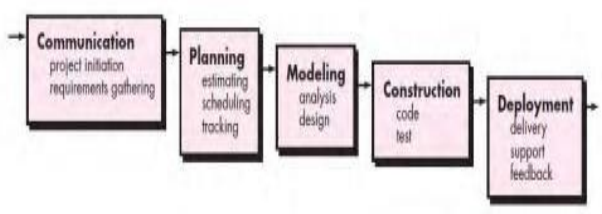

Gambar 1. WATERFALL MODEL

Berikut adalah gambar pengembangan perangkat lunak berurutan/ linear :

\section{Communication}

Langkah ini merupakan analisis terhadap kebutuhan software, dan tahap untuk mengadakan pengumpulan data dengan melakukan pertemuan dengan customer, maupun mengumpulkan data-data tambahan baik yang ada di jurnal, artikel, maupun dari internet.

Proses planning merupakan lanjutan dari proses communication (analysis requirement). Tahapan ini akan menghasilkan dokumen user requirement atau bisa dikatakan sebagai data yang berhubungan dengan keinginan user dalam pembuatan software, termasuk rencana yang akan dilakukan.

\section{Modeling}

Proses modeling ini akan menerjemahkan syarat kebutuhan ke sebuah perancangan software yang dapat diperkirakan sebelum dibuat coding. Proses ini berfokus pada rancangan struktur data, arsitektur software, representasi interface, dan detail (algoritma) prosedural. Tahapan ini akan menghasilkan dokumen yang disebut software requirement.

\section{Construction}

Construction merupakan proses dikenali oleh komputer. Programmer membuat kode. Coding atau akan menerjemahkan transaksi yang pengkodean merupakan penerjema- diminta oleh user. Tahapan inilah han desain dalam bahasa yang bisa yang merupakan tahapan secara 
nyata dalam mengerjakan suatu software, artinya penggunaan komputer akan dimaksimalkan dalam tahapan ini. Setelah pengkodean selesai maka akan dilakukan testing terhadap sistem yang telah dibuat tadi. Tujuan testing adalah menemukan kesalahan-kesalahan terhadap sistem tersebut untuk kemudian bisa diperbaiki.

III. HASIL DAN PEMBAHA-

\section{SAN}

- $\quad$ Flow Chart Sistem Informasi Pembayaran Administrasi Siswa

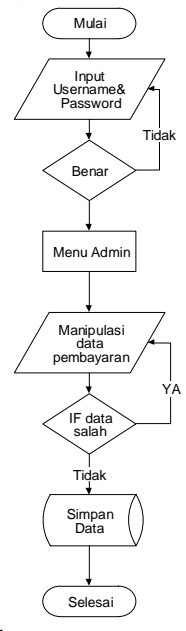

Gambar 2. FLOW CHART APLIKASI

SISTEM INFORMASI PEMBAYARAN SISWA

\section{Deployment}

Tahapan ini bisa dikatakan final dalam pembuatan sebuah software atau sistem. Setelah melakukan analisis, desain dan pengkodean maka sistem yang sudah jadi akan digunakan oleh user. Kemudian software yang telah dibuat harus dilakukan pemeliharaan secara berkala. 


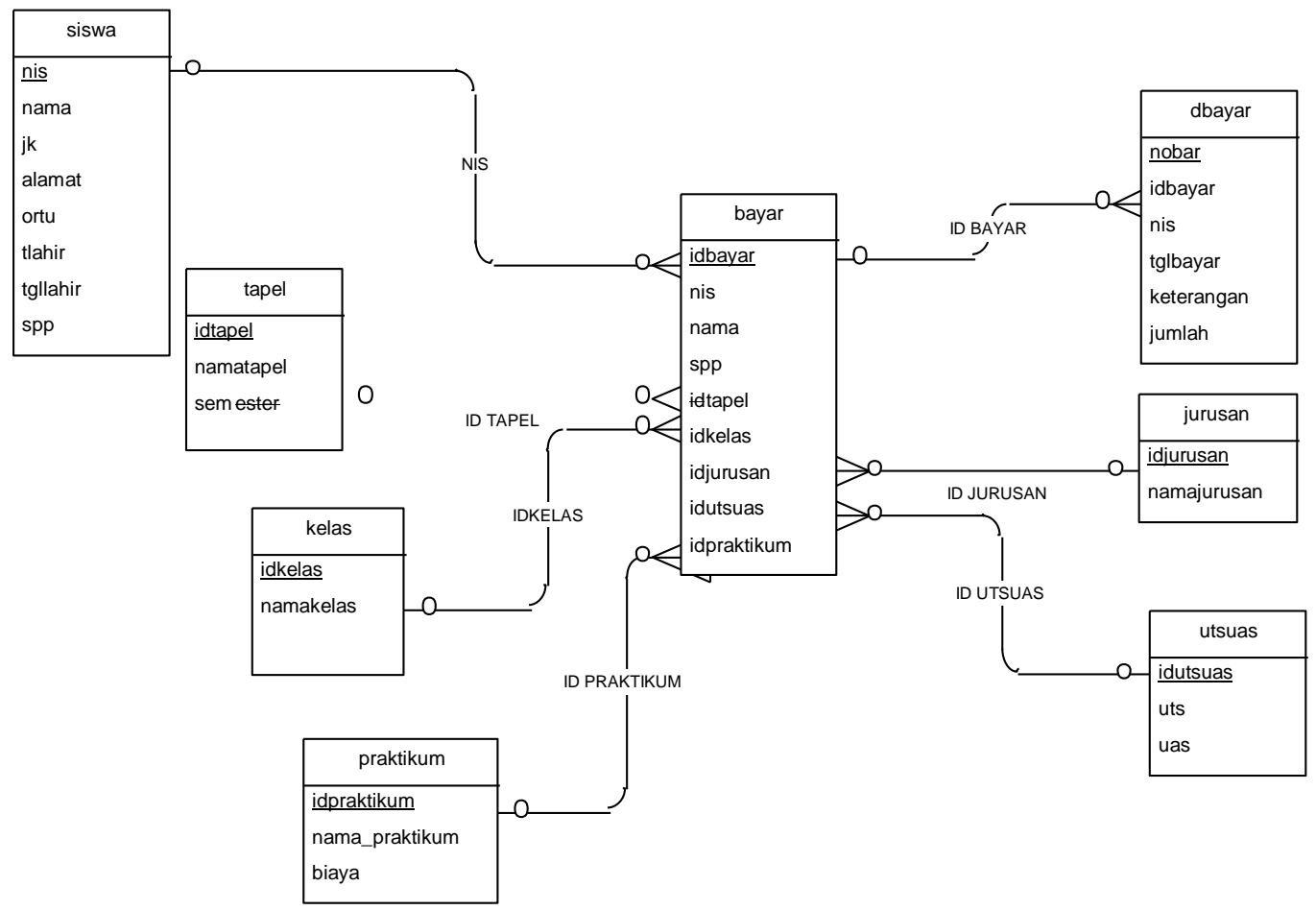

\section{RELASI DATA BASE}

- Data Flow Diagram 


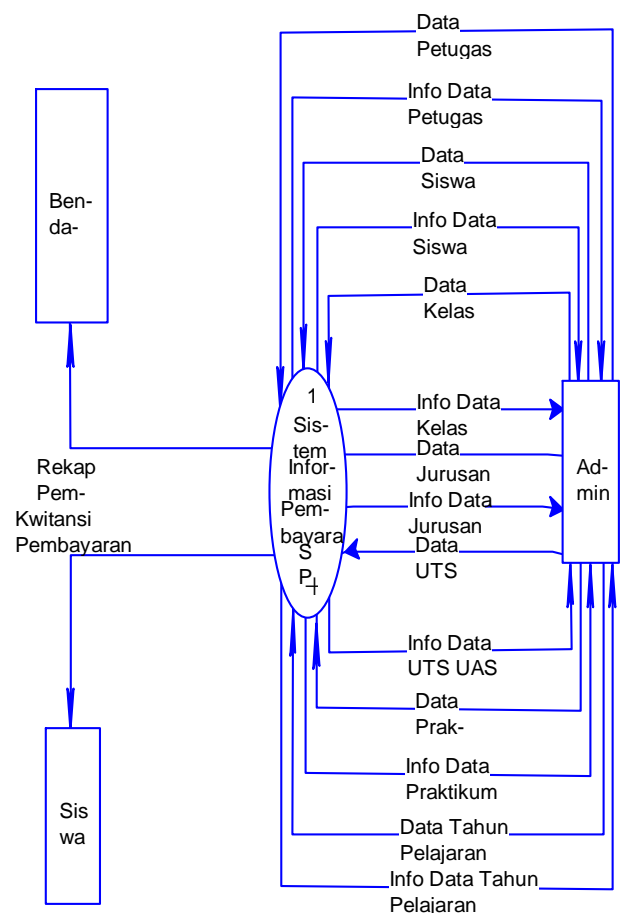

Gamabar 4 DAGIKON

- Implementasi Sistem

- Form Login

Pada form login ini operator harus memasukkan username dan password yang benar untuk dapat masuk ke menu utama sistem.

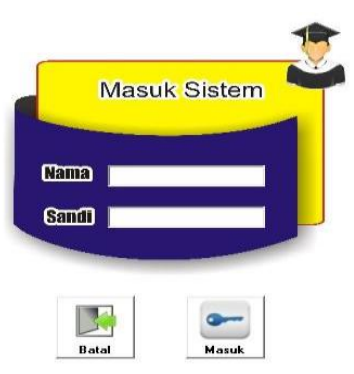

Form Menu Utama

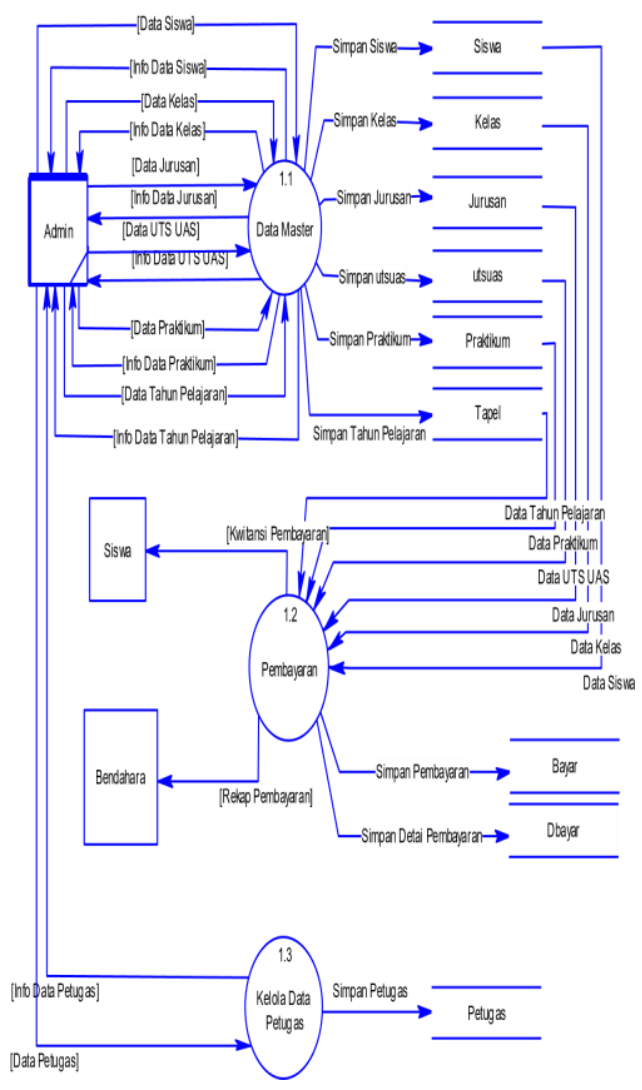

Gambar 5. DATA FLOW DIAGRAM LEVEL 1

Setelah operator Temasukkan username dan password yang benar kemudian klik tombol masuk. Untuk keluar dari sistem tekan tombol $\mathrm{Ba}$ tal. Tampilan form login dapat dilihat pada gambar berikut ini. Gambar 6. FORM LOGIN 
Terdapat 5 menu pada form menu utama yaitu master (form siswa,form kelas, form jurusan, form tahun ajaGambar 7. FORM MENU UTAMA

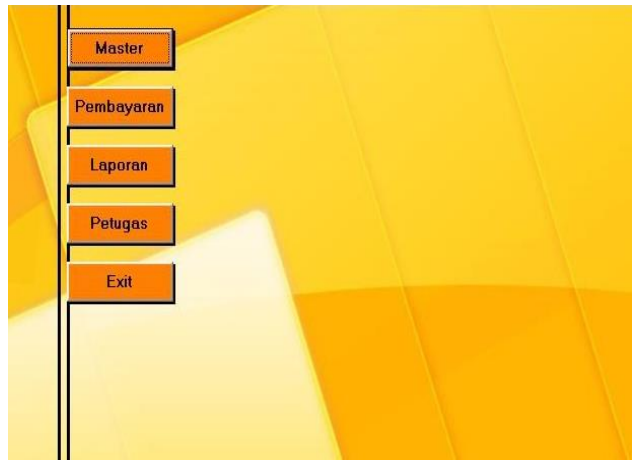

- $\quad$ Form Pembayaran

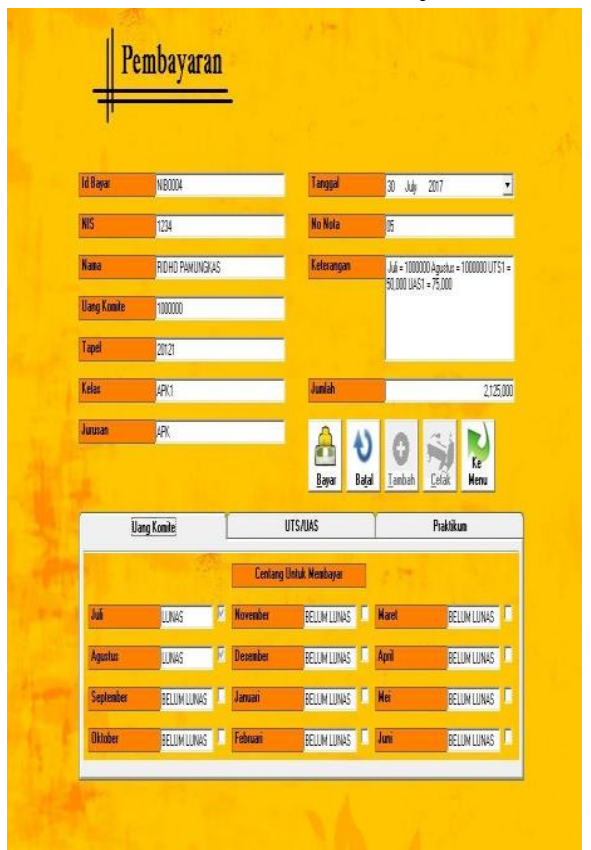

Gambar 8. FORM PEMBAYARA

\section{ID SECURITY}

QWTD4452377-ASP-5244107 ran, form uts/uas dan form praktikum), pembayaran, laporan, Petugas dan exit/keluar sistem. 


\section{KESIMPULAN DAN SARAN}

Dari hasil uji coba sistem yang dibangun dapat mempercepat dalam pencarian dan pengelolaan data-data laporan pembayaran administrasi siswa sehingga kinerja sistem lebih efektif dan akurat. Perangkat lunak sistem informasi pembayaran administrasi ini masih dapat di kembangkan seiring dengan perkembangannya dan kebutuhan pengguna sistem sehingga dapat mencapai hasil dan kinerja sistem yang lebih baik.

\section{DISKUSI}

Saya bersama teman saya bernama Asep mendiskusikan tentang Pembayaran SPP secara online menurut asep pembayarang yang dilakukan secara online sangat membantu dan memudahkan

\section{REFERENCE}

[1] O. M. Febriani and A. S. Putra, "Sistem Informasi Monitoring Inventori Barang Pada Balai Riset Standardisasi Industri Bandar Lampung," J. Inform., vol. 13, no. 1, pp. 90-98, 2014.

[2] A. S. Putra, "Paperplain: Execution Fundamental Create Application With Borland Delphi 7.0 University Of Mitra Indonesia," 2018. mahasiswa untuk melakukan pembayaran SPP.

Keuntungan pertama yang dirasakan jika kampus anda menggunakan akses pembayaran online adalah kenyamanan pembayaran bagi mahasiswa. Dengan bertransaksi online, mahasiswa anda tak perlu repot membawa uang tunai, karena transaksi ini dapat dilakukan secara langsung lewat ATM atau bahkan dengan menggunakan gadget dan akses internet.

Dengan bertansaksi secara online, semua mutasi anggaran kampus anda akan tercatat dengan baik, akurat serta dapat diakses kapan saja. Dengan begitu, para pegawai kampus anda dapat fokus dengan tugas yang lebih penting lagi, karena pencatatan sudah terekam. Jadi pelaporan ke pimpinan pun menjadi lebih mudah.

[3] A. S. Putra, "2018 Artikel Struktur Data, Audit Dan Jaringan Komputer,” 2018.

[4] A. S. Putra, "ALIAS MANAGER USED IN DATABASE DESKTOP STUDI CASE DB DEMOS."

[5] A. S. Putra, "COMPREHENSIVE SET OF PROFESSIONAL FOR DISTRIBUTE COMPUTING."

[6] A. S. Putra, "DATA ORIENTED RECOGNITION IN BORLAND DELPHI 7.0." 
"EMBARCADERO DELPHI

XE 2 IN GPU-POWERED FIREMONKEY

APPLICATION."

[8] A. S. Putra, "HAK ATAS KEKAYAAN

INTELEKTUAL DALAM DUNIA TEKNOLOGY BERBASIS REVOLUSI INDUSTRI 4.0."

[9] A. S. Putra, "IMPLEMENTASI

PERATURAN

PERUNDANGAN UU. NO 31 TAHUN 2000 TENTANG DESAIN INDUSTRI BERBASIS INFORMATION TECHNOLOGY."

[10] A

S. Putra, "IMPLEMENTATION OF PARADOX DBASE."

[11] A.

S. Putra, "IMPLEMENTATION OF TRADE SECRET CASE STUDY SAMSUNG MOBILE PHONE."

[12] A.

S. Putra, "IMPLEMENTATION

PATENT FOR APPLICATION WEB BASED CASE STUDI WWW. PUBLIKLAMPUNG. COM."

[13] A.

S. Putra, "IMPLEMENTATION SYSTEM FIRST TO INVENT IN DIGITALLY INDUSTRY."

[14] A. S. Putra, "MANUAL REPORT \& INTEGRATED
DEVELOPMENT

ENVIRONMENT

BORLAND DELPHI 7.0."

[15] A. S. Putra, "PATENT AS RELEVAN SUPPORT RESEARCH."

[16] A. S. Putra, "PATENT FOR RESEARCH STUDY CASE OF APPLE. Inc."

[17] A. S. Putra, "PATENT PROTECTION FOR APPLICATION INVENT."

[18] A. S. Putra, "QUICK REPORT IN PROPERTY PROGRAMMING."

[19] A. S. Putra, "REVIEW CIRCUIT LAYOUT COMPONENT

REQUIREMENT ON ASUS NOTEBOOK."

[20] A. S. Putra, "REVIEW TRADEMARK PATENT FOR INDUSTRIAL TECHNOLOGY BASED 4.0."

[21] A. S. Putra, "TOOLBAR COMPONENT PALLETTE IN OBJECT ORIENTED PROGRAMMING."

[22] A. S. Putra, "WORKING DIRECTORY SET FOR PARADOX 7."

[23] A. S. Putra, "ZQUERY CONNECTION IMPLEMENTED PROGRAMMING STUDI CASE PT. BANK BCA Tbk."

[24] A. S. Putra, D. R. Aryanti, and I. Hartati, "Metode SAW 
(Simple Additive Weighting) sebagai Sistem Pendukung Keputusan Guru Berprestasi (Studi Kasus: SMK Global Surya)," in Prosiding Seminar Nasional Darmajaya, 2018, vol. 1, no. 1, pp. 85-97.

[25] A. S. Putra and O. M. Febriani, "Knowledge Management Online Application in PDAM Lampung Province," in Prosiding International conference on Information Technology and Business (ICITB), 2018, pp. 181-187.

[26] A. S. Putra, O. M. Febriani, and B. Bachry, "Implementasi Genetic Fuzzy System Untuk Mengidentifikasi Hasil Curian Kendaraan Bermotor Di Polda
Lampung," SIMADA (Jurnal Sist. Inf. dan Manaj. Basis Data), vol. 1, no. 1, pp. 21-30, 2018.

[27] A. S. Putra, H. Sukri, and K. Zuhri, "Sistem Monitoring Realtime Jaringan Irigasi Desa (JIDES) Dengan Konsep Jaringan Sensor Nirkabel," IJEIS (Indonesian J. Electron. Instrum. Syst., vol. 8, no. 2, pp. 221-232.

[28] D. P. Sari, O. M. Febriani, and A. S. Putra, "Perancangan Sistem Informasi SDM Berprestasi pada SD Global Surya," in Prosiding Seminar Nasional Darmajaya, 2018, vol. 1, no. 1, pp. 289-294. 